\title{
CERTAIN NON-LINEAR DIFFERENTIAL POLYNOMIALS HAVING COMMON POLES SHARING A NON ZERO POLYNOMIAL WITH FINITE WEIGHT
}

\author{
ABHiJit BANERJEE AND GOUTAM HALDAR
}

Abstract. With the notion of weighted sharing we study the uniqueness property of meromorphic functions having common poles when certain non-inear differential polynomials share a non zero polynomial function. Our theorems in the paper will improve, extend and supplement a number of recent results in a more compact and convenient way.

Mathematics subject classification (2010): 30D35.

Keywords and phrases: uniqueness; meromorphic function; non-linear differential polynomials..

\section{REFERENCES}

[1] T.C.AlZahary And H.X.YI, Weighted value sharing and a question of I.Lahiri, Complex Var. Theory Appl. 49, 15 (2004), 1063-1078.

[2] A. BANERJEe, Meromorphic functions sharing one value, Int. J. Math. Math. Sci., 22, (2005), 35873598.

[3] A. BANerJee, On a question of Gross, J.Math.Anal.Appl., 327, 2 (2007), 1273-1283.

[4] M.L. FAnG AND H.L. QIU, Meromorphic functions that share fixed points, J. Math. Anal. Appl., 268, (2002), 426-439.

[5] W. K. Hayman, Picard values of meromorphic Functions and their derivatives, Ann. Math., 70, (1959), 9-42.

[6] W. K. Hayman, Meromorphic Functions, The Clarendon Press, Oxford (1964).

[7] I. LAHIRI, Value distribution of certain differential polynomials, Int. J. Math. Math. Sc., 28, (2001), 83-91.

[8] I.LAHIRI, Weighted sharing and uniqueness of meromorphic functions, Nagoya Math. J., 161, (2001), 193-206.

[9] I.LAHIRI, Weighted value sharing and uniqueness of meromorphic functions, Complex Var. Theory Appl., 46 (2001), 241-253.

[10] I.LAhIRI, On a question of Hong Xun Yi, Arch. Math. (Brno), 38, (2002), 119-128.

[11] P. LI AND C. C. YANG, On the characteristics of meromorphic functions that share three values CM, J. Math. Anal. Appl., 220, (1998), 132-145.

[12] X.Q.Lin, Further results on uniqueness of entire functions sharing one value, Rend. Sem. Mat. Univ. Politec. Torino, 69, 1 (2011), 37-49.

[13] L.Q.WANG AND X.D.LuO, Uniqueness of meromorphic functions concerning fixed points, Math. Slovaca, 62, 1 (2012), 29-38.

[14] J. WANG, W. LU AND Y. CHEN, Value sharing of meromorphic functions and their derivatives, Appl. Math. E-Notes, 11, (2011), 91-100.

[15] J.F. XU, F. LU And H.X. YI, Fixed points and uniqueness of meromorphic functions, Comput. Math. Appl., 59, (2010), 9-17.

[16] C.C.YAng, On deficiencies of differential polynomials II, Math. Z. Vol. 125, (1972), 107-112.

[17] C.C.YANG AND X.H.HUA, Uniqueness and value sharing of meromorphic functions, Ann.Acad. Sci. Fenn. Math., 22, (1997), 395-406.

[18] H.X.YI, On characteristic function of a meromorphic function and its derivative, INDIAN J. MATH., 33, 2 (1991), 119-133. 
[19] H. X. YI, Meromorphic functions that share one or two values II, Kodai Math. J., 22, (1999), 264-272.

[20] Q.C.ZHANG, Meromorphic function that shares one small function with its derivative, J.Inequal. Pure Appl. Math., 6, 4(2005), Art.116 [ ONLINE http://jipam.vu.edu.au/].

[21] X.Y.ZHANG AND W.C.Lin, Uniqueness and value sharing of entire functions, J.Math. Anal. Appl., 343, (2008), 938-950.

[22] X.Y.Zhang AND W.C.Lin, Corrigendum to "Uniqueness and value sharing of entire functions" (J.Math. Anal. Appl., 343, (2008), 938-950), J.Math. Anal. Appl., 352(2009), 971. 